\title{
RESENHA \\ A encruzilhada das ações afirmativas
}

Marcos Rodrigues ${ }^{1}$

MACHADO, Adilbênia Freire. Filosofia Africana: ancestralidade e encantamento como inspirações formativas para o ensino das africanidades. Fortaleza: Imprece, 2019.

Dentre as ações afirmativas, a filosofia africana começa a ocupar um espaço importante no âmbito das discussões acadêmicas, em sinal de inquietação com os efeitos nocivos da pedagogia eurocentrada vigentes até a atualidade. Daí a expectativa diante de pesquisas realizadas em busca de respostas a determinadas questões. Então, qual o lugar da filosofia africana nesta diáspora científica? o que esperar dessa ciência em termos de reparação cognitiva? Em que medida pode gerar benefícios ao ensino? Qual o engajamento político-pedagógico de gestores em ações inclusivas? Estaria o sistema educacional brasileiro atualizado a partir dos cursos de formação de professores?

Reflexões sobre essas e outras questões estão no livro Filosofia Africana: ancestralidade e encantamento como inspirações formativas para o ensino das africanidades, de Adilbênia Freire Machado, resultado da pesquisa desenvolvida no curso de mestrado em Educação pela Universidade Federal da Bahia. A abordagem etnográfica foi elaborada a partir da vivência no componente curricular optativo História e Cultura Africana e Afro-Brasileira do curso de Pedagogia (EDCB79). Sem dúvida, um volume para leitura crítica nos debates, nas rodas de conversa e nos estudos etnológicos sobre relações étnico-raciais que tratam das ações afirmativas.

Adilbênia Machado fez a diferença com sua pesquisa em forma de alerta sobre os paradigmas metodológicos para o cumprimento da Lei Federal 10.639/03 (complementada pela Lei Federal 11.645/08), que determina a inclusão do ensino da História e Cultura Africana e Afro-Brasileira nas redes oficiais de ensino. Com o recurso da linguagem poética, a autora inova na discussão, faz questionamentos, aponta elementos filosóficos de origem africana na diáspora como indicação de que os valores da maioria também precisam aparecer dentro de um sistema de aprendizagem contínua.

\footnotetext{
${ }^{1}$ Bacharel em Comunicação (1984); Mestre em Estudos Étnicos e Africanos pela Universidade Federal da Bahia (2012).
} 
A narrativa do encantamento delineada leva a crer que a Filosofia Africana constitui uma ação afirmativa libertária para o ensino brasileiro.

A leitura do livro é uma oportunidade de conhecer o perfil sedutor de uma intelectual que confessa seu encanto desde criança pela Filosofia Africana, temática que começou a pesquisar ainda na graduação. Decidiu usar a formação básica em filosofia como ferramenta de reparação para inverter o sentido de aplicação do ensino com base nos valores de ancestralidade e encantamento. Deslocou-se do Ceará para se entrosar na Bahia com as vivências, os saberes e as experiências da população e torná-los visíveis à luz do conhecimento científico em benefício de todos. Assim, apresenta a sua forma de contribuir com a política desse aprendizado.

A ideia de resenhar esse livro me reporta a um breve retrospecto de quando conheci Adilbênia Machado. Fomos colegas no Centro de Estudos Afro-Orientais (Ceao/UFBA), ambos na condição de aluno especial do Pós-Afro. Seguimos amigos parceiros de discussões por afinidade, até que, na primeira edição do Encontro O Mafro e Você, em 2013, convidei-a para participar de uma mesa com a abordagem Descolonizando Olhares, cujo conteúdo fazia parte da sua pesquisa no mestrado em Educação. Por último, não foi menos importante presenciar a defesa pública da sua dissertação e as recomendações da respectiva banca examinadora. Agora, o livro preenche uma lacuna significativa entre pesquisadores, professores, pensadores da pedagogia e acadêmicos interdisciplinares.

Ao longo do conteúdo, dois elementos se interpenetram entre o caminho e o método escolhidos: o racismo silencioso do ensino brasileiro e a luta pela implantação da lei de ações afirmativas na rede escolar. Desde o início, a autora leva o leitor a compreender que a educação brasileira seria mais inclusiva se fosse receptiva às possibilidades epistêmicas da Filosofia Africana baseadas na partilha do conhecimento pluralizado. O sistema de ensino estaria num nível de diálogo mais amplo com a sociedade caso renovasse sua visão de mundo e fizesse uso dos valores transversais da história e da cultura de origem africana. Estruturado em quatro capítulos, o livro transborda experiências, recheado de poesia, contos mitológicos, composições, entrevistas, depoimentos e provérbios que compartilham reflexões diversas e narrativas dialógicas.

O primeiro capítulo é dedicado a analisar a Lei Federal 10.639 e o currículo do curso de Pedagogia da Faculdade de Educação da UFBA. A autora sinaliza o paradoxo de um país delineado pelas marcas da democracia racial e um sistema de ensino 
atrasado após séculos de modelagem colonial. Destaca ainda o caráter eurocêntrico da formação de profissionais de educação sem valorizar a cultura da diáspora africana, em contraposição à lei que considera uma ferramenta de protesto à ideologia do discurso dominante, impregnada na bagagem pela ordem da eugenia, da marginalização e pelas manobras de silenciamento de uma população majoritária.

Num momento em que a negritude enfrenta o crivo do genocídio e a luta de implementação da Lei Federal 10.639/03, Adilbênia Machado se dispôs a investigar a trajetória curricular da Faculdade de Educação, trilhando caminhos epistêmicos até então desprezados pela classe dirigente do sistema educacional. As observações e as citações indicam que as teorias reproduzidas até o momento parecem não ir além dos conteúdos pré-estabelecidos cujo marco inicial é um paradigma histórico de datas e conquistas civilizatórias somente a partir do olhar europeu. A autora também se refere ao caráter formativo que apresenta o continente africano ainda como território único sem diversidade. Com isso, as metodologias aplicadas não favorecem o diálogo na escola sobre o direito à memória das populações secularmente subalternizadas e essa forma de ver o mundo dificulta a introdução de outros conteúdos devido ao racismo silencioso que ainda impera nos corredores acadêmicos.

O campo da pesquisa revela dados importantes, entre os quais destacamos: 1) ausência de componentes curriculares sobre história e cultura africana e afro-brasileira no curso de Pedagogia da UFBA, em 2009 e 2012; e 2) três componentes que aparecem no currículo como optativos, são de outras grades como história e antropologia. Nas entrelinhas, a autora faz entender que a universidade tem cumprido o papel de manter invisíveis corpos e referências negras, refletindo sobre o contexto, a criação da lei e sua não efetivação. Adilbência Machado apresenta uma leitura crítica da Lei Federal 10.639/03 em busca de inspirações na Filosofia Africana contemporânea para contribuir com outras possibilidades de inclusão.

A experiência empírica segue com percepções surpreendentes que, de algum modo, explicam a dificuldade em pensar outra sistemática além daquelas aplicações metodológicas cristalizadas nos livros didáticos. Então, a autora entra no segundo capítulo em estreito diálogo com a metodologia da teia dos odus, criada pelo professor Eduardo Oliveira, que apresenta o pensamento africano através da diversidade, na execução da troca de experiências, ao aprender e dialogar com a sabedoria dos nossos antepassados. O princípio básico de movimentar o corpo, a mente e a alma, com 
exercícios que trazem o encantamento, acompanha o método de leituras, interpretações, geração de outros olhares através da ludicidade.

A narrativa percorre os vários episódios ocorridos em sala de aula com o discurso afetivo da Filosofia Africana, como uma ciência de perspectiva ancestral, através da circularidade. É na roda que se ensina, compartilha e conhece o plano da igualdade, se aprende mutuamente, trocam-se experiências, sem excluir o conhecimento do outro. Com isso, a autora afirma o eixo principal da pesquisa: "pensar de que maneira a Filosofia Africana pode mediar o ensino da historia e cultura africana e afrobrasileira" (MACHADO, 2019, p. 217) somando o princípio de não separar o ensino da aprendizagem.

Com o apoio de referências, depoimentos e observações coletadas, a filósofa chama atenção para a influência das culturas de origem africana na sociedade brasileira desde a variação linguística, passando pela estética, culinária, religião, economia, com ações e experiências da vida cotidiana. Em consequência, sugere uma pedagogia que deve e pode ser praticada também fora da escola e do meio acadêmico, o que indica a necessidade de uma nova forma de ensino/aprendizagem a partir da unidade responsável pela formação de futuros professores, no caso a Faculdade de Educação.

No terceiro capítulo, o livro segue com uma narrativa libertária que destaca a filosofia e sua proposta de pensar desde a ancestralidade, cuja perspectiva é a do desejo de dialogar, compartilhar, aprender, praticar a alteridade. Na contramão da pedagogia colonizadora em vigor, a pesquisadora observa que, ao valorizar o que somos, é do encantamento frente à vida que nasce a Filosofia Africana e encanta o sentimento humano.

A discussão tece um alinhamento poético espiritualizado das idéias, cujos processos civilizatórios são negados e pouco aprofundados pela história. Ao perceber que o marco conceitual pedagógico brasileiro não aposta na capacidade da negritude em produzir conhecimento, a autora reforça que a Filosofia Africana propõe uma pedagogia assentada na experiência do olhar ancestral. E faz questão de relacionar as formas de compreensão da ação de filosofar, valorizar e reconhecer todas as vertentes envolvidas na alteridade.

Ainda na teia de argumentos, Adilbênia Machado insiste na reafirmação da influência africana em todas as fases históricas da cultura brasileira, antes, durante e depois do tráfico negreiro. E recomenda ver os africanos como produtores de conhecimento e epistomologias, urgência de revisão curricular para que o Ensino 
Superior se responsabilize também pelo ponto de partida, ou seja, capacitar os profissionais da educação, pois, no seu entendimento, a lei surge para contribuir e inverter esse olhar sobre as relações étnico-raciais.

Por fim, In-conclusões, como foi intitulado o último capítulo, deixa em aberto possibilidades de intervenção no modo de inspiração formativa para uma política pública de reparação na descolonização dos saberes, olhares e aprendizados. Se o conhecimento acontece no encontro e provoca o encantamento, então nada mais encantador do que apreender o que traz pertencimento para um recomeçar contínuo, reconstruir em movimento. A autora propõe com essa pesquisa a reversão do conteúdo linear, cronológico de uma estrutura pedagógica colonial perante um conjunto de ações para aplicação da Lei Federal 10.639/03 nas realidades escolares, visando uma educação contemporânea plural, democrática e antirracista.

O livro ocupa importante espaço entre as referências de estudo e pesquisa sobre o tema abordado e parece penetrar de formada oxigenada no campo das reparações metodológicas acerca das ações afirmativas, a partir dos princípios e teias da Filosofia Africana. A conclusão da leitura não encerra a pauta da discussão, deixa o encantamento como ponto de encruzilhada para questionar os efeitos de uma prática de dominação, buscar caminhos de renovação de conceitos e paradigmas, e facultar ao sujeito o direito de conhecer a própria história.

Artigo recebido em 02 de junho de 2020. Aprovado em 30 de junho de 2020. 